Inner dial words conforming functional comprehensive unstructured
Middle dial words socio-economic methodological statistical hypothetical
Outer dial words policies beliefs strategies frameworks

and so on, for a total of 36 words on each dial.

There is no copyright on the Health Education Jargon Generator. As it is simply a bit of fun, and available free of charge, Church \& Cronin probably felt no need for such protection. All the same, they deserve the credit for their work.

PO Box 1415

I. O. AZUONYE

London NW6 $5 Y W$

\title{
Reference
}

Church, M. \& Cronin, A. (1979) The Health Education Jargon Generator. Geneva: International Journal of Health Education.

\section{Inappropriate language}

\section{DeAR Sirs}

Any attempt by European psychiatrists to understand patterns of emotional distress and treatment with which they are unfamiliar is surely welcome. May I protest, however, at the approach and language adopted by Dr Rands (Psychiatric Bulletin, November $1989,13,622-625$ ) in the account of her trip to Malawi. It is far from clear what sort of information is being communicated through an idiom of "superstitious and jealousy-ridden population"; "shiny black faces"; "the characteristic smell of Malawi sweat"; "frenzied"; "extraordinary"; "essential primaeval rhythm". This is not ethnographic description, it is racist stereotype.

University College \&

ROLAND LitTlEWOOD

\section{Middlesex School of Medicine}

Riding House Street, London WIN 8AA

\section{Miscellany}

\section{New publications}

The Ethnic Minority Health Bulletin is the first information service to cover the mental, physical and social aspects of health care of ethnic minority people in the United Kingdom. The annual subscription is $£ 25$ ( $£ 45$ for two years). Further information: Christine Gardiner, Editor, Ethnic Minority Health Bulletin, Lynfield Mount Hospital, Heights Lane, Bradford, W. Yorks BD9 6DP.

The Arab Journal of Psychiatry is published under the auspices of the Arab Federation of Psychiatrists provisionally in November and May each year. Original papers, reviews, case reports and brief communications in all fields of psychiatry are invited. The annual subscription is $\$ 25$. Further information: Dr Adnan Takriti, Editor, The Arab Journal of Psychiatry, POB 5370, Amman, Jordan.

\section{Reports}

The Report on the Eleventh Year (1 October 1988-30 September 1989) of the Alcohol Research Group is available from the Department of Psychiatry, University of Edinburgh, Kennedy Tower, Morningside Park, Edinburgh EH 10 5HF. It includes information on the Group's Survey of Drinking Habits among Teenagers in England and its project on the Development of Alcohol Education for Schools.

The Annual Report, 1988-1989, of the North West Fellowship for the Support of Schizophrenia Sufferers and Their Families is available from the Fellowship at 46 Allen Street, Warrington, Cheshire WA2 7JB and includes details of the Fellowship's projects. 